DEPARTAMENTO DE PATOLOGIA E CLINICAS CIRÜRGICA E OBSTETRICA

Diretor: Prof. Dr. Ernesto Antônio Matera

\title{
INVERSÃO DO UTERO E DA VAGINA, COMPLICADA COM PROLAPSO DA BEXIGA, DURANTE O PARTO, EM CADELA *
}

(INVERSION OF UTERUS AND VAGINA IN PARTURITION, COMPLICATED WITH PROLAPSE OF BLADDER, IN A BITCH)

\author{
A. V. StopigliA \\ Assistente \\ J. S. Marcondes Veiga \\ Assistente voluntário \\ 1 estampa ( 3 figuras)
}

Uma das ocorrências mais graves que podem sobrevir no curso do parto é, indubitàvelmente, aquela provocada pelo prolapso de órgãos genitais, acompanhado ou nāo de outras complicações sôbre os mesmos ou então sediadas em visceras que mantêm com êles relações de contigüidade.

Efetivamente, a inversão e o prolapso do útero e da vagina, constituem fenômenos obstétricos bastante sérios.

Embora o acidente possa ocorrer durante a gestação e mesmo em fêmeas nuliparas, é, entretanto, consequiência precípua da parturição ou do abortamento. Mais precisamente, sobrevém durante ou logo após a expulsão fetal e mesmo decorridos alguns dias, em razão do colo uterino permanecer aberto. Registre-se a propósito a referência de VATTI, citando Johnk, na qual faz menção a 12 casos de prolapso uterino, em éguas, ocorridos antes do parto.

Quanto à incidência, trata-se de alteração que não se observa com a mesma freqüência entre as várias espécies domésticas; nas vacas ocorre mais freqüentemente, sobretudo nas boas fêmeas leiteiras, sendo raro na égua e, ainda mais, nas pequenas fêmeas ruminantes, porca e, excepcional, nas carnivoras (Bournay, Cadiot e Almy, Williams, StrauNard, Graig, Garcia, Mensa, Galli, Benesch e Wright).

O prolapso útero-vaginal pode, embora com mais raridade, estar acompanhado também do da bexiga, agravando o acidente. Esta lesão é verificada na vaca e raramente na égua e na cadela. Citam-se ob-

* Trabalho apresentado à X* Conferência Anual, patrocinada pela Sociedade Paulista de Medicina Vetcrinária, em Sāo Paulo, de 8 a 11 de setembro de 1955. 
servaçōes de Coquot, Revière, Youatt, Arvant, Schumacher, Violet, Raynard e MENSA, todos referidos pelo último, sem todavia, pormenorizar a incidência por espécie.

O comprometimento da bexiga, ocorre sobretudo quando há solução de continuidade ou dilaceraçāo do pavimento da vagina, seguida de contrações expulsivas.

Não obstante êste assunto integrar capitulo bem estudado e amplamente discutido nos Tratados de Patologia Cirúrgica e Obstétrica, pobre é a casuistica existente a respeito.

Com efeito, a perquirição bibliográfica a nosso alcance, demonstra inexistência de relatos na literatura nacional e mesmo escassez na estrangeira no que concerne ao assunto em aprêço, nas cadelas. Fazem exceção, as referências de Mathis em 1900 (cit. por Bourvay), de Whipple (1932), de Jennings (1935) e de HodgmaN (1936), todos, entretanto, relativos apenas a prolapso de vagina. Infelizmente o trabalho de Schulze (1947), sôbre "Prolapso do útero e vagina ex animais carnivoros", citado no Index Veterinarius, nāo pôde ser consultado, a despeito de nosso empenho.

A observação que dá motivo à nossa comunicação, constitui pelas suas caracteristicas especiais um caso excepcional e, portanto, acreditamos digno de ser relatado.

Referimo-nos à ocorrência de inversão uterina-vaginal, com prolapso de bexiga, em cadela, durante o trabalho de parto.

\section{OBSERVAÇĀO}

Em 11 de Maio de 1955, foi encaminhada ao Scrviço de Clinica Cirúrgica e Obstétrica da Faculdade, cadela, sem raça definida, de $2 \frac{1}{2}$ anos de idade, de pelagem amarela e branca, registrada sob $n^{\circ} 1575$.

A fêmea apresentava-se cm trabalho de parto desde a véspera, sem, contudo, expelir fetos. A presença de grande tumefação prêsa aos genitais externos, levou c proprietário a solicitar os serviços profissionais adequados.

Do ponto de vista de antecedentes gerais, nada de importância a mencionar; como antecedentes obstétricos, informaçāo de duas gestaçōes anteriores. seguidas de parto e de puerpério normais.

Ao exame verificamos: animal em bom estado de nutriçāo, porém $\mathrm{cm}$ prostraçāo.

Mucosas aparentes de coloração rósca. Temperatura retal $39^{\circ}$. Pulso 144 pulsaçōes por minuto c bulhas cardiacas fortes; 25 movimentos respiratórios na unidade de tempo. 
Abdome distendido. A palpação revela formaçōes que lembram a fetos. Ausencia de contraçōes uterinas. Batimentos cardiacos fetais presentes. Mamas túrgidas e com presença de secreçāo láctea.

Os órgãos genitais externos, cujo aspecto, aliás, despertava a atenção, mostravam: rima vulvar exageradamente dilatada, permitindo a passagem de formaçāo globosa, proeminente, de superfície lisa, de coloração vermelha congesta, em alguns pontos violácea, recoberta em partes por sujilades e excrementos fecais, com forma de cone truncado e de consistencia mole e flutuante $\mathrm{cm}$ sua maior porção (fig. 1). A extremidade livre deșta parte túmida aprescntava depressāo convexiforme, na qual havia, centralmente, uma abertura corrcspondente, o mais provável, ao lúmen do corpo uterino com presença de feto insinuado.

O animal em decúbito dorsal, permitia verificar na face ventral da tumefação, um orifício irregularmente pregucado c cuja exploraçāo com sonda para cateterismo vesical de cadela, deixou sair grande quantidade de urina.

Após o esvaziamento da bexiga, determinando accntuada redução do volume ila tumefação, identificamos ainda pela inspeçāo e, em seguida pela palpação, a presença de soluçāo de continuidade de aproximadamentc $3 \mathrm{~cm}$, com scde na face esquerda da parte em prolapso, e correspondente ao corpo do útero, próximo à cervix.

O exame levado a cfeito, permitiu-nos diagnosticar a afecçāo como se tratando de inversão do útero e da vagina, complicada com prolapso da bexiga.

A presença de partes necrosadas nos órgāos exteriorizados, agravada pela rutura do corpo uterino, incitaram-nos a fazer como melhor indicação o tratamento cirúrgico: laparotomia com ovário-histerectomia total e colpopexia.

\section{OPERAÇÃO}

Como preparação prévia ao ato cirúrgico, realizamos a antissepsia dos órgãos expostos, seguida de extração manual do feto insinuado, com seus ancxos, cuja traçāo, aliás, foi relativamente fácil. Em seguida houve a redução da parte em prolapso.

Apús a aplicação de $2,0 \mathrm{ml}$ de Demerol, o animal foi contido $\mathrm{cm}$ decúbito dorsal e submetido a anestesia geral pelo éter em máscara de circuito aberto.

Técrica - Preparado o campo operatório, pelos processos habituais, procedemos à laparotonia mediana, retroumbelical, com incisão de aproximadamente $12 \mathrm{~cm}$.

A seguir, inspeção da cavidade e reposiçāo das visccras ectópicas, por manobras suaves, para as suas respectivas posições anatômicas.

Exccutada a exposiçāo dos cornos uterinos grávidos (fig. 2), por técnica comum, foram pinçados os pedículos útero-ovarianos, pelo processo das três pinças de Kelly, seccionados com tesoura e ligados com fio de algodāo duplo.

Desinserção dos ligamentos largos do útero, seccionando-os com tesoura, precedida, porém, pela laqucadura dos vasos com fio de algodão.

Antes de realizarmos a secção do corpo uterino, logo abaixo do ponto que apresentava a rutura, tivemos o cuidado prévio de procedcrmos à ligadura das artérias uterinas posteriores de ambos os lados, também com fjo de algodão. 
Iniciamos o tratamento do côto utcrino, suturando-o em dois planos, com fio de algodão $n^{\circ} 0$, montado $\mathrm{cm}$ agulha atraumática. A primeira - perfurante -. por meio de uma sutura de Schimieden e a segunda - scromuscular, asséptica com sutura de Cusching.

Posteriormente, fizemos a peritonizaçāo, ancorando os ligamentos largos, anteriormente desinseridos, sôbre o côto uterino, já ocluido.

Completando a operaçāo, e obedecendo técnica prèviamente estabclecida, fizemos a colpopexia, fixando a vagina - por meio de três pontos separados com fio de algodão atravessando a sua camada seromuscular - na borda dos planos profundos da ferida operatória.

Finalmente, cfetuamos a reconstituição anatômica das estruturas, suturando os planos profundos, em massa, com pontos scparados de fio de algodão, e a pele, com sutura intradérmica continua em ziguezague conforme MATERA e colaborador (1950).

Proteçāo da ferida operatória com bandagem curativa, estéril c sēca.

No pós-operatório, que decorreu normalmente, aplicaçáo de antibiótico (Dibiotyl $0,50 \mathrm{~g}$ ) c antitóxico (Hepatocaico), de 24 em 24 horas, por via subcutánca, durante 3 dias.

Cicatrização "per primam" decorridos 7 dias, recebendo o animal alta por cura e encontrando-se em perfeito estado, até a claboração do presente trabalho (fig. 3).

\section{DISCUSSÃO}

O estudo das paratopias, particularmente no respeitante aos órgāos uro-genitais, oferece pontos interessantes e suscetiveis de discussão.

Com efeito, enquanto em ruminantes o prolapso do útero c geralmente acompanhado de inversāo completa, na porca e na cadela, em razão de disposição anatômica própria, isto è, ausência dos ligamentos intercornuais, a estrofia é parcial, comprometendo apenas um corno. Convém citar ainda neste particular a assertiva de BENESCH e WRICHT, os quais frisam, que na cadela, a inversāo uterina se faz geralmente de um só corno, antes mesmo de ter expulsado completamente os fetos do outro corno.

Conforme acentuamos anteriormente, os deslocamentos do útero, da vagina e da bexiga, sobretudo no puerpério, sāo minuciosamente considerados pelos vários tratadistas em seus compêndios especializados. Sem embargo, não apresentam os mesmos, unanimidade de pontos de vista, em relação aos conceitos que implicam na definiçāo das diversas modalidades de paratopias. Senão vejamos:

Williams afirma em sua obra de Doenças dos órgãos Genitais: "Entre os autores existe uma lamentável confusāo, com respeito ao significado de inversão e prolapso do útero, pois tal inversão e prolapso, 
não são mais do que estádios de um deslocamento. Quando a inversão progride até deslocar o órgão proeminentemente através da vulva, se denomina com maior propriedade prolapso".

Muitos autores de Tratados de Patologia Veterinária, entre os quais figuram alguns clássicos, definem de um modo geral o reviramento do útero como sendo a saída do órgão desenvaginado pela fenda vulvar, de tal sorte que a mucosa forma seu invólucro externo, atribuindo a esta afecçāo indiferentemente as seguintes denominaçōes: prolapso, procidência, inversão, retroversão e retropulsão (BouRNAY, CADIot e ALMY, Graig, Garcia, BabCock, Brunsley).

A maioria dos autores, todavia, procura conceituar melhor os processos, definindo-os separadamente, a fim de torná-los distintos. Para ĉstes, de um modo geral, a denominação de prolapso ou procidência, seria reservada para a saída de víscera, normalmente contida em cavidades, através de uma abertura natural; enquanto que estrofia, extroversão, extroflexão, inversão, seriam têrmos sinônimos e aplicáveis nos casos de paratopias especiais ligados a um reviramento de órgão ôco, de tal maneira que a superficie externa se torna interna e vice-versa (Baldoni, Hendrickx, Fröhner e Silbersiepe, Williams, Mensa, LeiNati, Cinotti, VatTi).

Torna-se mister, ainda, à guisa de elucidação, expor o conceito defendido por GalLI, que chama a atenção para os têrmos que muitos consideram como sinônimos: prolapso e procidência. Considera êle, que ambos fazem parte do mesmo grupo de paratopias, mas sāo afecçōes distintas entre si: procidência é a saída de uma víscera através de uma solução de continuidade recente, provocada nos tecidos, enquanto que prolapso ć a saída de uma víscera através de uma abertura natural, pelo afrouxamento dos meios próprios de fixaçāo.

Em abono de seu ponto de vista, reclama, de acôrdo com o significado lingüistico, para procidência o sentido de descontinuidade (procaedo $=$ corte adiante $)$, enquanto no têrmo prolapso $($ pro-labi $=$ relaxamento adiante), é implícito o sentido de afrouxamento.

Em caráter de ilustração, convém notar que IGARZABal, em seu Tratado de Patologia Cirúrgica Humana, faz nítida distinçāo entre prolapso e procidência, no que concerne às afecçōes do reto.

Em razăo do exposto, parece-nos lícito esposar o conceito dos autores cuja opinião categorizada admite que a inversão pode estar ou não acompanhada de prolapso; no primeiro caso, os órgãos entram em contato com o mundo exterior, revestidos pela sua túnica interna, mu- 
cosa. Está claro também, a nosso ver, que os órgãos simplesmente em prolapso, perdem apenas as suas relaçôes de continuidade, porém apresentam-se ao exterior com a topografia de suas camadas imutável. No caso em aprêço, isto ocorreu com a bexiga.

Em conclusão, trata-se, no presente trabalho, de um caso de inversāo útero-vaginal, com prolapso de bexiga, verificada durante o parto, de causa espontânea, pois não houve nenhum agente ativo que pudesse favorecer a lesāo.

Sua apresentação justifica-se pela natureza excepcional da ocorrência em cadela, e pelo êxito no tratamento levado a efeito.

\section{RESUMO}

Os autores focalizam no presente trabalho, caso de inversão uterina-vaginal, complicada com prolapso da bexiga, durante o trabalho de parto, em cadela.

Após fazerem consideraçōes gerais sôbre ocorrências desta natureza nas várias espécies animais, passam em revista os poucos casos descritos na bibliografia à mão, concluindo pela exigüidade de publicações na literatura nacional e estrangeira, no que concerne às fêmeas carnivoras.

A seguir descrevem a observação clínica pessoal, a operação levada a efeito, com os respectivos pormenores da técnica que julgaram mais indicada para o tratamento do caso em aprêço: laparotomia com ovário-histerectomia e colpopexia. Cite-se a propósito, o êxito obtido com o emprêgo do fio de algodão como material exclusivo utilizado para laqueadura dos vasos e suturas dos órgãos e estruturas anatômicas.

Ao ensejo, fazem comentários sôbre as paratopias dos órgãos urogenitais e discutem a diversidade existente de conceitos e denominações para êstes deslocamentos, esposando, finalmente, a opiniāo da maioria dos autores, os quais fazem distinção entre prolapso e inversão.

Concluem pela raridade da ocorrência na espécic canina e pelo sucesso no tratamento operatório sugerido.

\section{SUMMARY}

A case of inversion of uterus and vagina in parturition complicated with prolapse of bladder in a bitch, has been reported in this paper by the authors. 
After referring the cases in all animals species recorded in the available literature, they have concluded that works on this subject are not so common as far as female dogs and cats are concerned.

The clinical report and the operative surgery carried out as oophorohysterectomy and colpopexy have been described.

The use of cotton thread as suture material for this operation, ligating the blood vessels and suturing the genital organs has shown very good results.

The ectopia of urinary and genital organs has been discussed and the difference between the words prolapse and inversion has been commented in agreement with the opinion of the most of authors.

They have concluded by the success of the surgical treatment attained of this condition.

\section{BIBLIOGRAFIA}

ВАвсоск, W. W. - 1944 - Principles and practice of surgery : 1083. Philadelphia, Lea \& Febiger

BaldoNI, A. - 1916 - Manuale di patologia e terapia chirurgica: $3: 247-55$. $2^{\bullet}$ ed. Milano, Francesco Vallardi

BeNESCH, F. and J. G. WRIGHT - 1950 - Veterinary obstetrics: 388-92. London, Baillière, Tindall and Cox

Berthelon, M. - 1951 - La chirurgie gynécologique et obstétricale des femelles domestiques: 241-71. 2ème éd. Paris, Vigot fréres

Bournay, J. -1900 - Obstetrique vétérinaire: 401-16. Paris, J. B. Baillière et fils

BRUMLEY, O. V. - 1950 - A text-book of the diseases of the small domestic animals: 198-9. Philadelphia, Lea \& Febiger

Cadiot, P. J. et J. ALMY - 1924 - Traité de therapeutique chirurgicale des animaux domestiques : $2: 383-8 ; 528-31 ; 549-61$. 3ême éd. Paris, Vigot frères

Cinotti, F. - 1948 - Patologia e terapia chirurgica veterinaria: 379-81; 433-4. Milano, Francesco Vallardi

Frönner, F. e E. Silbersiere - 1933 - Compendio de patologia quirurgica para veterinarios: $166-7 ; 190-1 ; 198-9.2^{4}$ ed. española. Barcelona, Revista Veterinaria de España

GAlLI, A. - 1948 - Pagine di ostetricia e ginecologia veterinaria: 173-84. Piza, Vallerini Editore

Galscli Alfonso, C. -1944 - Obstetricia veterinaria: 494-509. $2^{\circ}$ ed. Madrid, Imprenta Biosea 
Craig, J. F. - 1937 - Fleming's veterinary obstetrics: 460-90. 4th ed. London, Baillière Tindall and Cox

Hendrickx, F. - 1922 - Précis du cours de pathologie chirurgicale: 67-9; 336. Bruxelles, Imprimeric G. Bothy

Hobday - 1947 - Hobday's surgical diseases of dog and cat: 275; 321. 5th ed. Baltimore, The William \& Wilkins Co.

Hodcman, S. F. J. - 1936 - Prolapse of the vagine in a bitch. Vet. Rec., 48 (23): :743

IGARZABAL, J. E. - 1946 - Tratado de patologia quirurgica: 4:3621-35. Buenos Aires, Libreria Hachette S.A.

Leinsti, L. - 1948 - Compendio di anatomia patologica degli animali domestici: 542-55. $2^{*}$ ed. Milano, Casa Editrice Ambrosiana

Matera, E. A. e A. V. Stopiglia - 1950 - Sutura intradérmica na cirurgia dos pequenos animais. Rev. Fac. Met, Vet., S. Paulo, $4(2): 363-8$

MENSA, A. - 1947 - Patologia chirurgica veterinaria: 1:354-7; $2: 748-51 ; 871-4$. 2' ed. Torino, Unione Tipografico-Editrice Torincse

VatTI, G. - 1948 - Ginecologia ed ostetricia veterinaria: 202-3; 305-13. $2^{4}$ ed. Napoli, Raffaele Pironti e figli

WILLIaMS, W. L. - 1936 - Ostetricia veterinaria: 399-414. Milano, Ulrico Hocpli

WiLliams, W. L. - 1942 - Enfermedades de los organos genitales de los animales domesticos: 587-8. Barcelona, Salvat Editores

_- 1943 - Whipple's operation for prolapse of the vagina in bitches. J.A.V.M.A., $103(800): 286-7$ 


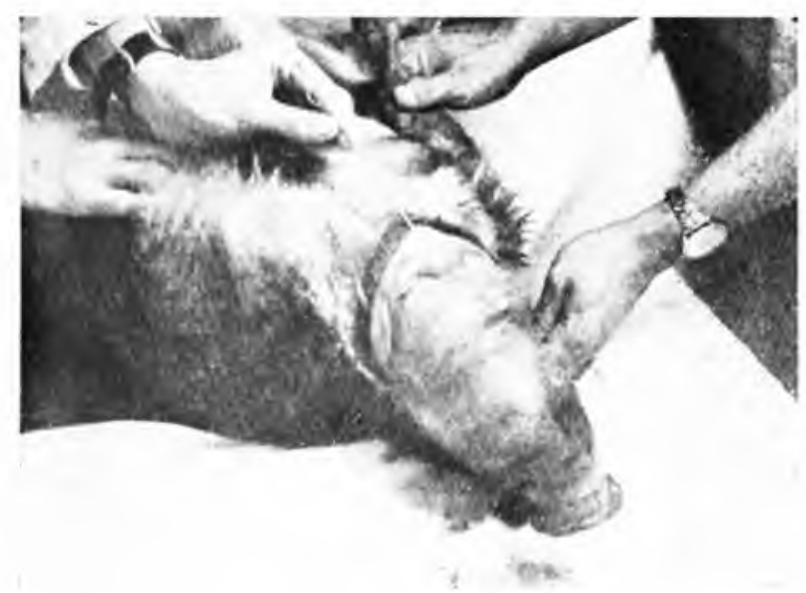

Fig. 1
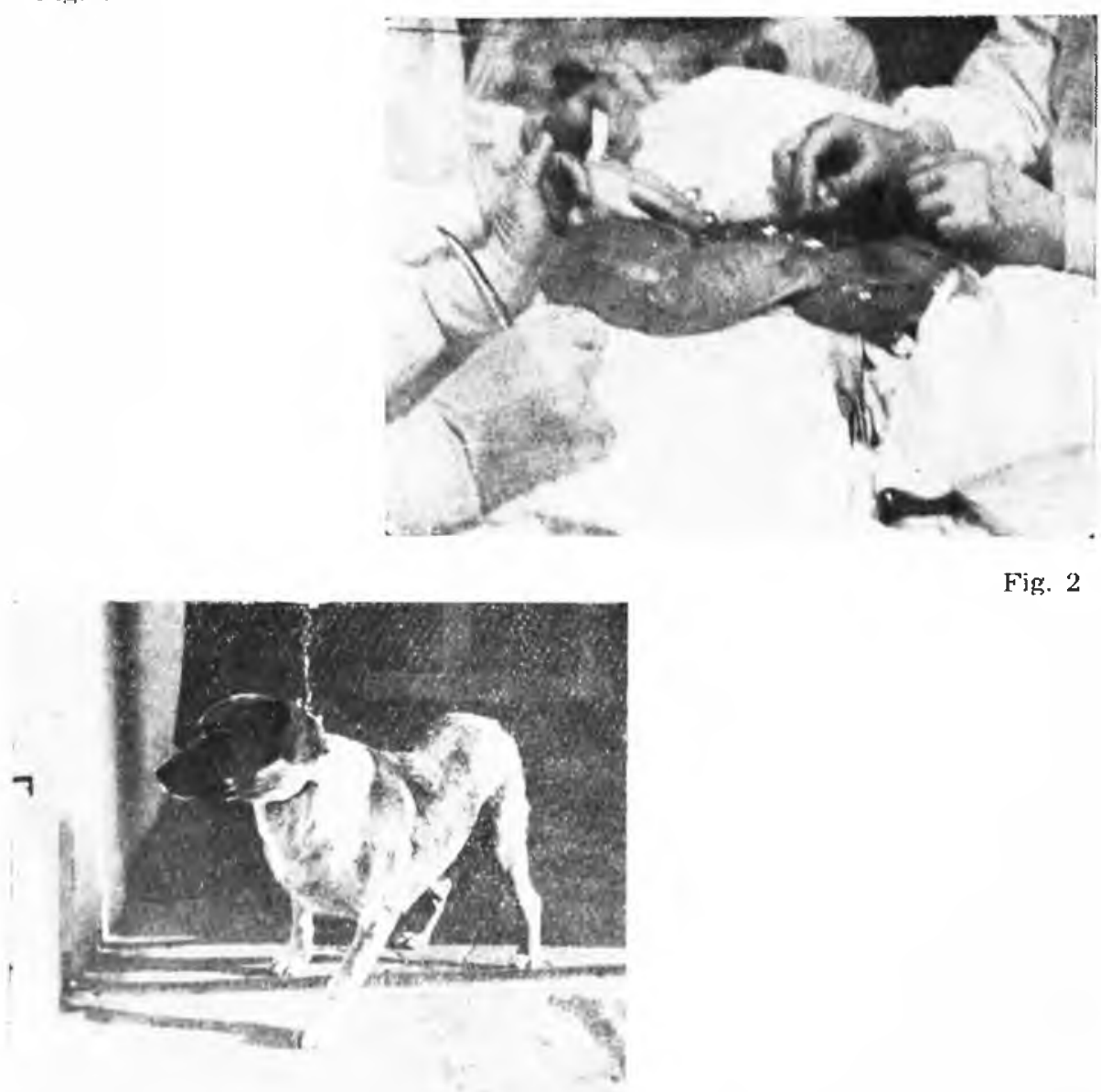

Fig. 2 